\title{
Short Review of Multichannel Membrane Capacitive Deionization: Principle, Current Status, and Future Prospect
}

\author{
Nayeong Kim ${ }^{1}$, Jiho Lee ${ }^{2}$, Seonghwan Kim ${ }^{3}{ }^{\circledR}$, Sung Pil Hong ${ }^{1}$, Changha Lee ${ }^{1}$, Jeyong Yoon ${ }^{1,4}$ \\ and Choonsoo Kim ${ }^{5, *(D)}$ \\ 1 School of Chemical and Biological Engineering, College of Engineering, Institute of Chemical Process, Seoul \\ National University (SNU), Gwanak-gu, Daehak-dong, Seoul 151-742, Korea; kimmy0421@snu.ac.kr (N.K.); \\ dhaos86@snu.ac.kr (S.P.H.); leechangha@snu.ac.kr (C.L.); jeyong@snu.ac.kr (J.Y.) \\ 2 Water Cycle Research Center, Korea Institute of Science and Technology, Hwarang-ro 14-gil 5, Seongbuk-gu, \\ Seoul 02792, Korea; leejiho153@kist.re.kr \\ 3 Samsung Research, Samsung Electronics, Seoul R\&D campus, 56 Seongchon-gil, Seocho-gu, Seoul 06765, \\ Korea; sh9641.kim@samsung.com \\ 4 Korea Environment Institute, 370 Sicheong-daero, Sejong 30147, Korea \\ 5 Department of Environmental Engineering and Institute of Energy/Environment Convergence Technologies, \\ Kongju National University, 1223-24, Cheonan-daero, Cheonan-si 31080, Korea \\ * Correspondence: choonsoo@kongju.ac.kr
}

Received: 30 December 2019; Accepted: 15 January 2020; Published: 18 January 2020

\begin{abstract}
Capacitive deionization (CDI) has gained a lot of attention as a promising water desalination technology. Among several CDI architectures, multichannel membrane CDI (MC-MCDI) has recently emerged as one of the most innovative systems to enhance the ion removal capacity. The principal feature of MC-MCDI is the independently controllable electrode channels, providing a favorable environment for the electrodes and enhancing the desalination performance. Furthermore, MC-MCDI has been studied in various operational modes, such as concentration gradient, reverse voltage discharging for semi-continuous process, and increase of mass transfer. Furthermore, the system configuration of MC-MCDI has been benchmarked for the extension of the operation voltage and sustainable desalination. Given the increasing interest in MC-MCDI, a comprehensive review is necessary to provide recent research efforts and prospects for further development of MC-MCDI. Therefore, this review actively addresses the major principle and operational features of MC-MCDI along with conventional CDI for a better understanding of the MC-MCDI system. In addition, the innovative applications of MC-MCDI and their notable improvements are also discussed. Finally, this review briefly mentions the major challenges of MC-MCDI as well as proposes future research directions for further development of MC-MCDI as scientific and industrial desalination technologies.
\end{abstract}

Keywords: water treatment; ion separation; capacitive deionization; cell design; and multichannel flow stream

\section{Introduction}

Capacitive deionization (CDI) has drawn increasing interest in water desalination, wastewater treatment, and resource recovery [1-4]. CDI is considered more versatile than other water treatment technologies because it is an energy-efficient and eco-friendly process that does not require extreme temperatures or pressures or use of chemicals [5-8]. Along with the simplicity of the process, the relatively small size of the module allows for simple adaptation for decentralized water treatment and in combination with other desalination technologies, including multistage flash distillation and reverse osmosis $(\mathrm{RO})[9,10]$. 
Over the last few decades, CDI has become remarkably advanced with various types of electrodes including capacitive electrodes with carbonaceous materials (i.e., activated carbon, carbon aerogel, carbon nanotubes, and graphene) [11-15] and faradaic electrodes with battery and battery-like materials (i.e., sodium manganese oxide, molybdenum disulfide, Mxene, silver/silver chloride, and Prussian blue analogs) [16-20]. These electrode materials have led to novel systematic developments. For instance, with the modification of carbonaceous electrodes, flow-by CDI [21], flow-through CDI [22], and inverted CDI (i-CDI) [23] were introduced. With the development of faradaic electrodes, hybrid CDI (HCDI) [16,24], cation intercalation desalination (CID) [25], rocking-chair CDI (RCDI) [17], and desalination battery (DB) [26] have been widely researched. Instead of a static electrode, the flowable electrode was employed in CDI, resulting in a continuous desalting system such as flow-electrode CDI (FCDI) [27] and fluidized bed CDI [28]. In addition, the introduction of ion exchange membranes in CDI (MCDI) allowed not only enhanced desalination capacity and charge efficiency by blocking the co-ion repulsion but also a significantly improved stability by reducing the side reactions such as oxygen reduction and carbon oxidation reactions [1,29].

In particular, the systematic development in CDI has been accelerated by the theoretical approaches to understand the electrochemical behavior of ions on the porous carbonaceous electrodes. For instance, the modified Donnan model is considered as fundamental knowledge of the ion sorption mechanism on porous electrodes, which explains the desalination performance and the relationship among charges, feed concentrations, and operation voltages [30]. Several theoretical studies discovered that the desalination performance of CDI was directly related to a correlation of the pore size distribution and the ion removal capacity [31]. All of these theoretical investigations provide one of the most important criteria for choosing an appropriate material and for considering the synthetic method of electrodes in CDI.

Nevertheless, CDI suffers from the following fundamental limitations: (1) CDI is plausible for treating low concentrated water (ex. Brackish water) compared with other water treating technologies such as the RO. (2) However, such low feed salinity causes the limited ion removal capacity because the electrical double layer (EDL) could not be sufficiently formed in the nanopores of the porous electrodes. (3) CDI in aqueous media is operable only in a narrow range of operational cell voltage $\left(\mathrm{E}_{\text {cell }}<1.23 \mathrm{~V}\right.$ vs. normal hydrogen electrode, NHE), and thus the choice of electrodes as well as ion removal capacity are severely restricted [1,2]. Recently, in order to overcome these limitations, multichannel flow stream membrane CDI (MC-MCDI) was proposed as an innovative concept of cell design in CDI. MC-MCDI utilizes two independent flow streams for electrodes and treating water, resulting in a favorable environment for the formation of EDL [15,32-35]. Through several systematic studies, MC-MCDI has not only successfully been demonstrated as an alternative of conventional CDI systems, but also utilized in various applications. Therefore, this review actively described the major principles of MC-MCDI including schematics and operational methods and addressed its applications. To gain a better insight into MC-MCDI, conventional CDI was also intensively studied in terms of standard analysis metrics as well as various types of cell designs. The major challenges and future research direction for further development of MC-MCDI are also discussed.

\section{Capacitive Deionization (CDI)}

\subsection{Basic Principle and Operational Features}

CDI is an electrochemical ion separation process using not only the ion ad/desorption into the EDL formed on the capacitive electrodes [1] but also faradaic reactions of pseudo-capacitive and battery electrodes [4]. Commonly, CDI is comprised of a pair of porous electrodes such as activated carbons, current collectors, and a channel for treating water [2], which is a simple cell structure to stack multiple cells for industrial applications.

Conventional CDI is operated in two consecutive steps, the charging and discharging processes (Figure 1). During the charging step (purification of water by inducing electrical energy), ions in 
aqueous media are removed by the adsorption within the EDL or by faradaic reactions such as intercalation, pseudo-capacitive, and redox reactions [8]. During the discharging step, (regeneration of electrodes by the electrical short-circuit or the reversed electrical energy), the immobilized ions are released, leading to the production of concentrated effluent [18]. Consumed energy during the charging step could be partially recovered during the discharging step, as encountered in energy storage devices. $\mathrm{CDI}$ is a considerably more energy-efficient process than other desalination technologies [36,37].

Charging Step

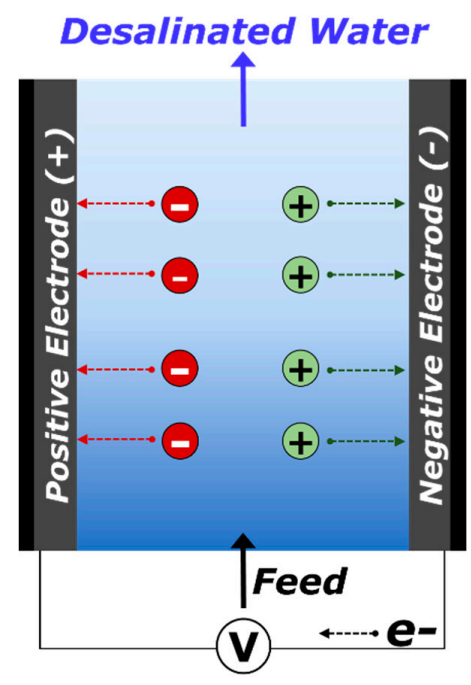

Discharging step

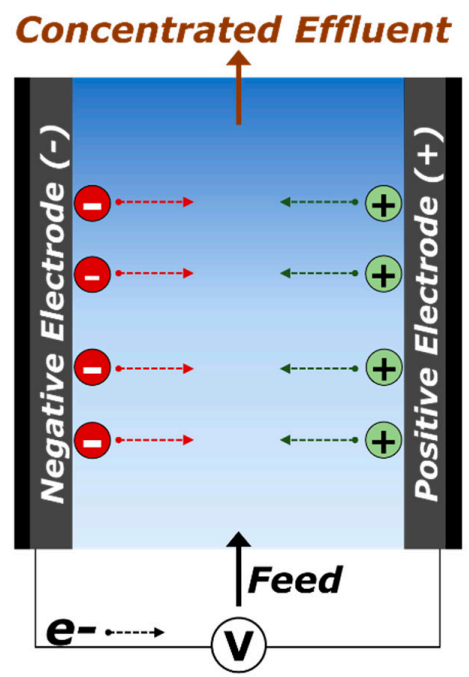

Figure 1. Schematic illustration of basic cell configurations and operations in capacitive deionization (CDI).

\subsection{Standard Analysis Metrics}

The desalination performance of CDI is often determined by standard analysis metrics such as salt adsorption capacity (SAC), salt adsorption rate (SAR), charge efficiency, and energy consumption (Table 1) [1,2]. SAC represents the amount of removed ions divided by the total mass of electrode materials during the charging process (Equation (1)). In particular, the maximum salt adsorption capacity (mSAC, SAC obtained at the equilibrium state) is useful to explore the sorption capacity without the influence of system parameters. Note that the SAC is affected by the operational conditions [1]. SAR expresses the ratio of removed ions to the operation time (Equation (2)) to show the rate capability of the system. Since the SAR is influenced by various operational parameters, including cell architecture, electrode thickness, porosity, and pore structures, it is a useful parameter to optimize the system [38]. Then, the correlation between SAC and SAR can be presented in the CDI Ragone, allowing systematic understandings and comparisons among several types of CDI systems [39].

$$
\begin{gathered}
\operatorname{SAC}(\mathrm{mg} / \mathrm{g})=\frac{M_{\mathrm{NaCl}} \cdot \int\left(C_{0}-C_{t}\right) \cdot v \cdot d t}{m} \\
\operatorname{SAR}(\mathrm{mg} / \mathrm{g} / \mathrm{s})=\frac{M_{\mathrm{NaCl}} \cdot \int\left(C_{0}-C_{t}\right) \cdot v \cdot d t}{m_{w w} \cdot t}
\end{gathered}
$$

where $C_{0}$ and $C_{t}$ are the initial and effluent concentrations $(\mathrm{mM})$ which were converted from the measured conductivities, $v$ is the volumetric flow rate $(\mathrm{L} / \mathrm{min}), \mathrm{M}_{\mathrm{NaCl}}$ is the molecular weight of $\mathrm{NaCl}$ $(\mathrm{g} / \mathrm{mol}), \mathrm{m}$ is the total mass of the carbon electrodes $(\mathrm{g}), m_{w w}$ is the total mass of the working electrodes $(\mathrm{g})$, and $t$ is the operation time for the charging step or the total desalination cycle(s).

Charge efficiency and energy consumption are the parameters to evaluate how efficiently CDI is operated (Equations (3) and (4)). Charge efficiency is derived by the ratio of the removed ions 
to the invested electric charge, while the energy consumption represents the energy required to remove a single ion $[1,2]$. Since the charge efficiency shows the degree of electric charge utilized to remove the ions, it is a major index to determine the presence of parasite reactions as well as energy consumption [40]. The energy consumption in $\mathrm{kT}$ is the thermodynamic energy consumption based on the specific Gibbs free energy of separation, offering the scientific evidence to compare the energy efficiency of CDI systems with that of other desalination technologies [41].

$$
\begin{gathered}
\text { Charge efficiency }=\frac{S A C \cdot \mathrm{m}}{M_{\text {Nacl }}} /\left(\frac{\int I d t}{F}\right) \\
\text { Energy consumption }(k T)=\frac{V}{n} \int I d t \text { (at CV mode), } \frac{I}{n} \int V d t \text { (at CC mode) }
\end{gathered}
$$

where $F$ is the Faradaic constant $(96,485 \mathrm{C} / \mathrm{mol}), I$ is the current (A) during the charging step, $V$ is the voltage $(\mathrm{V})$, and $n$ is the total number of ions desalinated during the operation. $1 \mathrm{kT}$ is equivalent to $2.48 \times 10^{3} \mathrm{~J} / \mathrm{mol}$ for the case of removing $\mathrm{NaCl}$. Note that $\mathrm{CV}$ stands for the constant voltage operation, while CC stands for the constant current operation.

Table 1. Standard analysis metrics in CDI.

\begin{tabular}{ccc}
\hline & Unit & Definition \\
\hline Salt adsorption capacity (SAC) & $\mathrm{mg} / \mathrm{g}_{\text {electrode }}$ & Ion removal capacity \\
Salt removal rate (SAR) & $\mathrm{mg} / \mathrm{g}_{\text {electrode }} / \mathrm{s}$ & Rate capability \\
Charge efficiency & $\%$ & Ratio of removed ions to the invested electric charge \\
Energy consumption & $\mathrm{kT}$ & Energy consumption per removed ion \\
\hline
\end{tabular}

\subsection{Operational Mode}

There are two types of electric operational modes: Current control or voltage control (Table 2). For the charging step, the system could be operated by either the constant current (CC) or the constant voltage $(\mathrm{CV})$. Note that the $\mathrm{CV}$ mode is widely used in CDI operation due to the practical advantages such as easy to execute and fast ion removal rate, whereas the CC mode results in the consistent quality of desalinated water using less energy [36]. During the discharging steps, there are three types of operational modes, such as reversed current, zero voltage (short-circuit), and reversed voltage modes. Zero voltage operation is the most commonly used operation for the regeneration of electrodes without consuming extra energy. For the complete regeneration of certain electrodes, reversed current or voltage modes could be used $[15,17]$.

Along with the electric operational modes, there are three conditions for flowing the feed solutions: Semi-batch, single-pass, and batch modes. The system with the semi-batch mode is fed the solution from the reservoir where the treated water is re-entered (Figure 2). It is often used to analyze the equilibrium state for different electrode materials or systems [2,34]. For more practical approaches, the single-pass mode is introduced, in which the feed solution continuously inflows so that the equilibrium concentration is reached at the end of the ad/desorption processes [1,34]. Batch mode refers to the system feeding a certain volume of the feed solution, and thus the concentration of feed solution keeps decreasing $[17,42]$. Between the three processes, batch mode is the simplest operation mode, while the single-pass mode is the most common for the practical studies.

Table 2. Types of electric operational modes in capacitive deionization (CDI) for charging and discharging steps.

\begin{tabular}{ccc}
\hline System Operation Mode & Current & Voltage \\
\hline Charging & Constant current $(\mathrm{CC})$ & Constant voltage $(\mathrm{CV})$ \\
Discharging & Reversed current & Zero voltage \\
& & Reversed voltage \\
\hline
\end{tabular}


Semi-batch mode

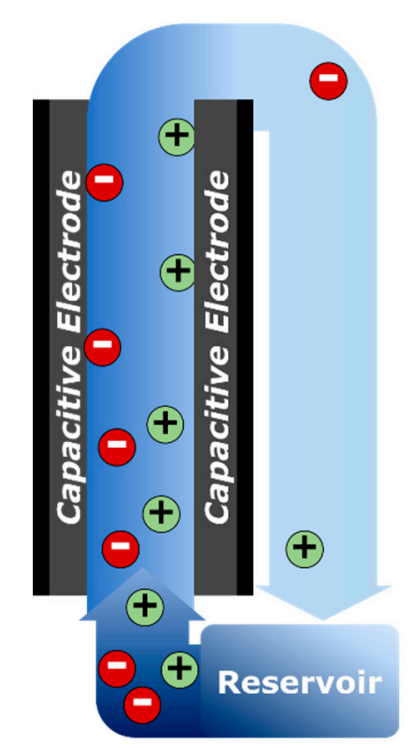

Single-pass mode

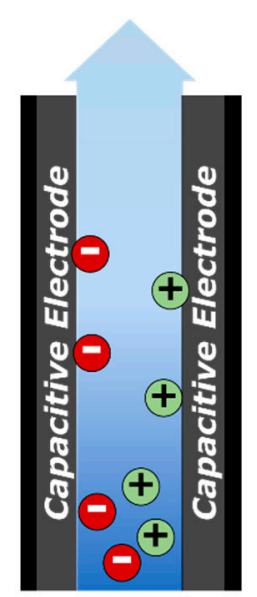

\section{Batch mode}

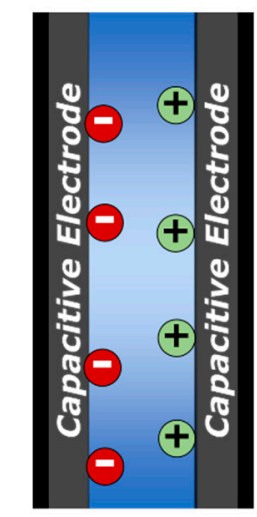

Figure 2. Conditions for flowing the feed solutions: Semi-batch, single-pass, and batch modes.

\subsection{Advancement of Capacitive Deionization (CDI) and Its Limitations}

CDI is developed in various types of electrodes and architectures, as depicted in Figure 3. First, electrodes can be categorized by two ion removal mechanisms: The capacitive and faradaic electrodes. In the category of capacitive electrodes, the EDL is formed on the surface of the electrode by applying electrical energy. Therefore, without charge transfer reactions, the ions are preferentially ad/desorbed into the EDL formed at the interface of the electrode surface and the water stream [4]. Porous carbonaceous materials like activated carbon, activated carbon fiber, carbon aerogels, carbon nanotube, and graphene have been utilized as capacitive electrodes, and they are widely used as electrodes in conventional CDI [11]. In the category of faradaic electrodes, the ions favorably interacted with the surface and lattice of the electrodes, resulting in the insertion of the ions into the lattice structures by the changing oxidation state or redox reactions. Accordingly, their ion removal capacity can be much larger than that of capacitive electrodes [43]. Battery and battery-like materials such as sodium manganese oxide, Prussian blue analogs, 2D materials (e.g., Mxene, titanium disulfide, and molybdenum disulfide), and silver/silver chloride have been utilized as faradaic electrodes in CDI $[4,18,20]$.

Second, the classification of electrodes originates from the mobility of the electrodes. Instead of static-electrodes, flow-able conductive particles have been employed in CDI cell architectures, known as flow-electrode CDI (FCDI) [1,27]. This concept is similar to the slurry-based energy storage systems, such as electrochemical flow capacitors and semi-solid lithium-ion batteries. The FCDI exhibits two major unique features and functionalities compared with the static-electrode CDI cell architecture: (1) FCDI is able to desalinate feed water continuously because the charged activated carbon particles can be sustainably discharged downstream of the cell, and (2) a continuous supply of discharged carbon particles leads to a higher ion adsorption capacitance than static-electrode CDI. Therefore, FCDI can desalinate highly concentrated feed water.

The introduction of ion exchange membranes not only allows a significant enhancement of desalination performance in conventional CDI but also leads to various types of cell architectures such as hybrid CDI (HCDI) [16], cation intercalation desalination (CID) [25], multichannel flow stream membrane CDI (MC-MCDI) [15], and battery desalination combined with the oxidation processes [44]. Due to the permselective characteristics of ion exchange membranes, membrane-involved CDI reveals high charge efficiency and enhanced salt removal capacity. By reducing co-ion repulsion and ion swapping (Figure 4), additional ions could be captured to balance the charge neutrality in the macropores of electrodes or at the interface of membranes and electrodes [30]. 
Static Electrode

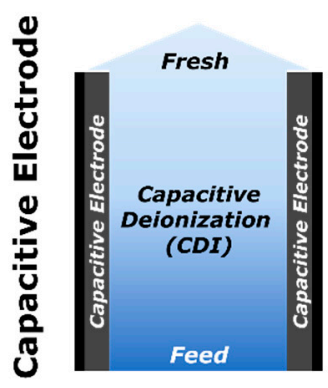

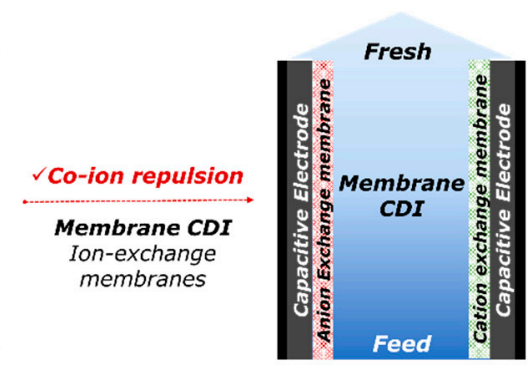

Flow Electrode

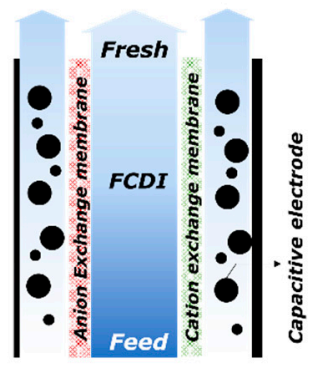

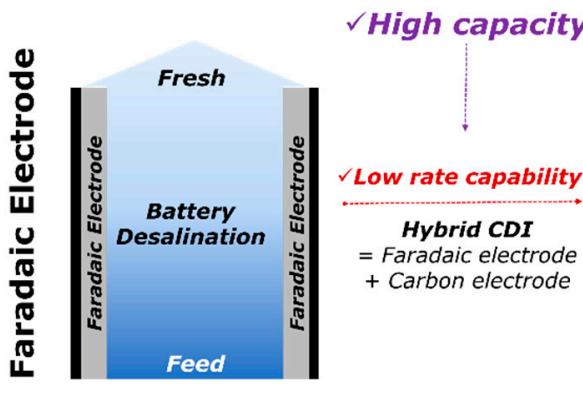

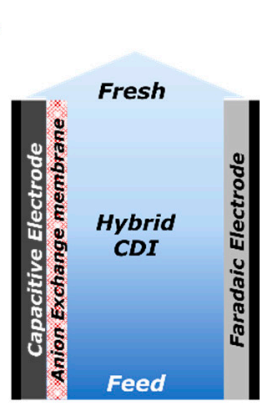

$\checkmark$ Continuous operation Flow-electrode CDI Flow type electrodes

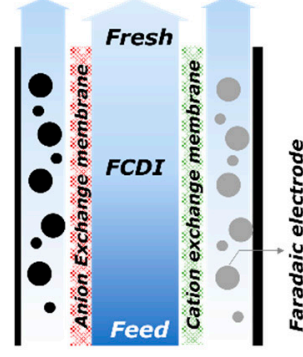

Figure 3. Fundamental development of the cell architectures in CDI using the static and flow electrodes.

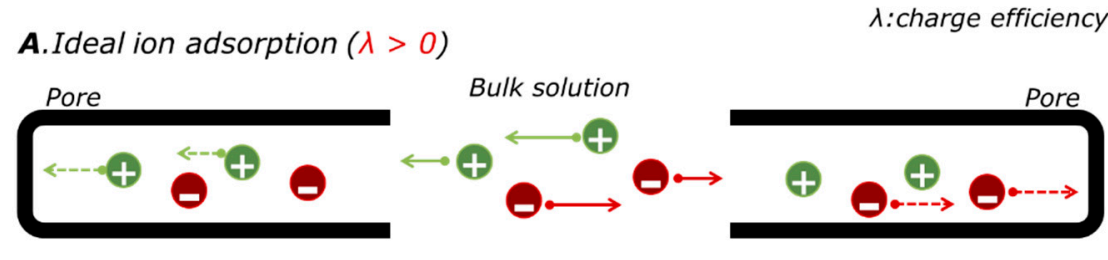

B.Ion swapping $(\lambda=0)$

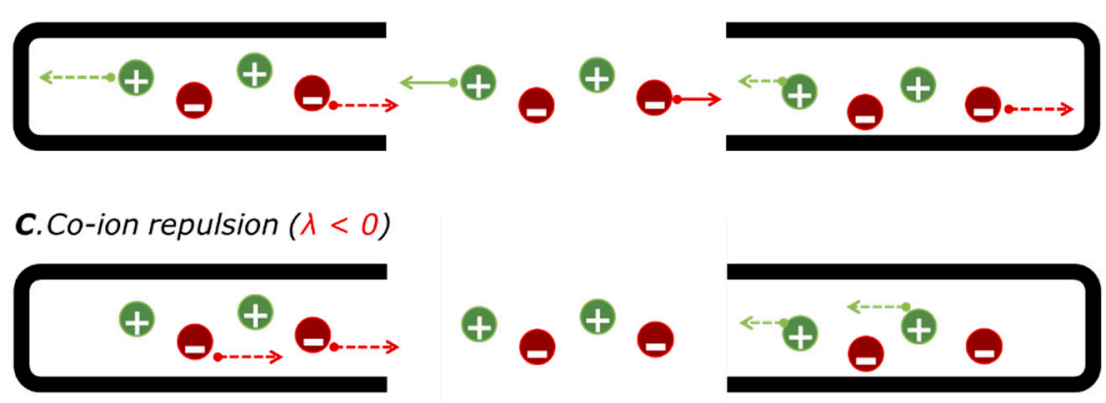

Figure 4. Ion removal mechanism of CDI with charge compensation on pores in the porous carbon electrode: (A) Ideal ion adsorption, (B) presence of the ion swapping, and (C) presence of the co-ion repulsion.

Despite of numerous efforts on the advancement of electrode materials and architectures, CDI has crucial limitations for its industrial applications as listed below:

\section{- Discontinuous desalination process}

Conventional static-electrode CDI is operated in a sequential charging and discharging steps, resulting in the production of fresh and concentrated water, respectively. This intermittent operation causes discontinuous production of clean water [45].

\section{- Low concentration of the feed water}

For most of static-electrode CDI, the energy consumption strongly depends on the salt concentration of the feed water because CDI desalinates ions from the feed water, while other desalination technologies 
like reverse osmosis and multi-stage flash separate water molecules from the ions [1]. Thus, CDI is compatible and energy-efficient only for desalinating low concentrated feed solutions. However, low feed salinity hinders the formation of the EDL in the nanopores of the porous electrodes, resulting in limited ion removal capacity [5].

\section{- Limited operation voltage regime}

Despite the significant development of electrode materials and cell architectures, the CDI operation is limited to the operational voltage of approximately $1.23 \mathrm{~V}$ vs. NHE due to the theoretically stable potential window in aqueous media without side reactions [33]. Assuming that the EDL capacitor is proportional to the cell voltage, CDI seldom holds the SAC over $20 \mathrm{mg} / \mathrm{g}$.

\section{- Limitation of Flow-electrode CDI}

Although FCDI has overcome several limitations seen in the static-electrode CDI, it is also hindered by various obstacles, including relatively high energy consumption associated with the regeneration of the charged carbon particles, agglomeration of the carbon slurry, and extremely low conductivity of the flow electrodes [1]. It is evident for the FCDI system that the leakage currents can never be as small as those observed in static-electrode systems, which reduces the overall efficiency of the system.

\section{Multi-Channel Membrane CDI (MC-MCDI)}

\subsection{Cell Configuration and Key Advantages}

To overcome the limitations of static- and flow-electrode CDI, a unique cell architecture, known as MC-MCDI, has recently been designed (Figure 5). The MC-MCDI cell consists of the middle and the side channels as the feed and electrode channels, respectively. The two channels were separated by a pair of anion and cation exchange membranes (AEM and CEM) (Figure 5A). In the side channels, porous carbon electrodes are attached to current collectors made of titanium mesh. The side of the current collector is coated with rubber to press on the ion exchange membrane and seal the middle and the side channels (Figure 5B,C). As such, both the feed stream and electrolyte can be independently controlled, providing a favorable environment for the formation of the EDL. The cell design of MC-MCDI involves several advantages and has distinctive features compared to the conventional CDI architectures as follows:

\section{- Enhanced desalination performance}

MC-MCDI involves an advantageous configuration of the membrane CDI (Figure 5A). For example, the major benefits of membrane CDI are the enhancement of charge efficiency and salt removal capacity because the added membranes block co-ion repulsion, which causes the undesirable current during the charging step. As shown in Table 3, MC-MCDI results in enhanced SAC compared with MCDI and $\mathrm{CDI}$, showing a two to five times greater ion removal capacity. Moreover, the system maintains high charge efficiency $(>90 \%)$, indicating that the system is operated efficiently with a small amount of side reactions. Additionally, by using concentrated solutions in the side channels, the porous electrodes could form the EDL even in nanopores, therefore, enhancing the ion removal capacities [15].

\section{- Semi-continuous desalination}

Two stream channels in MC-MCDI allow for semi-continuous production of clean water, thereby overcoming one of the major limitations for the static-electrode CDI. As mentioned, for the static-electrode CDI, the repeated cycling between adsorption and desorption causes discontinuous production of fresh water [45]. In the case of MC-MCDI, however, separated middle and side channels could be alternately desalinated and regenerated. In other words, one channel is desalinated, while the other channel is regenerated. Therefore, the cell can produce clean water regardless of the charging and discharging processes, resolving the limitation of intermittent CDI operation [32]. 


\section{- Multifunctional system}

MC-MCDI could be utilized not only in the desalination of brackish water but also in cases such as purification of highly concentrated feed water, up-concentration of certain ions, and possibly selective ion removal. For instance, the MC-MCDI system can be used for treating the concentrated wastewater from the reverse osmosis process. It could also be used for up-concentration of valuable ionic contents such as $\mathrm{Li}^{+}$and $\mathrm{Co}^{2+}$, as well as for desalting $\mathrm{KOH}$ and $\mathrm{H}_{2} \mathrm{SO}_{4}$ or $\mathrm{NaCl}$ and $\mathrm{KCl}$ by changing operating conditions without using any additional industrial processes.
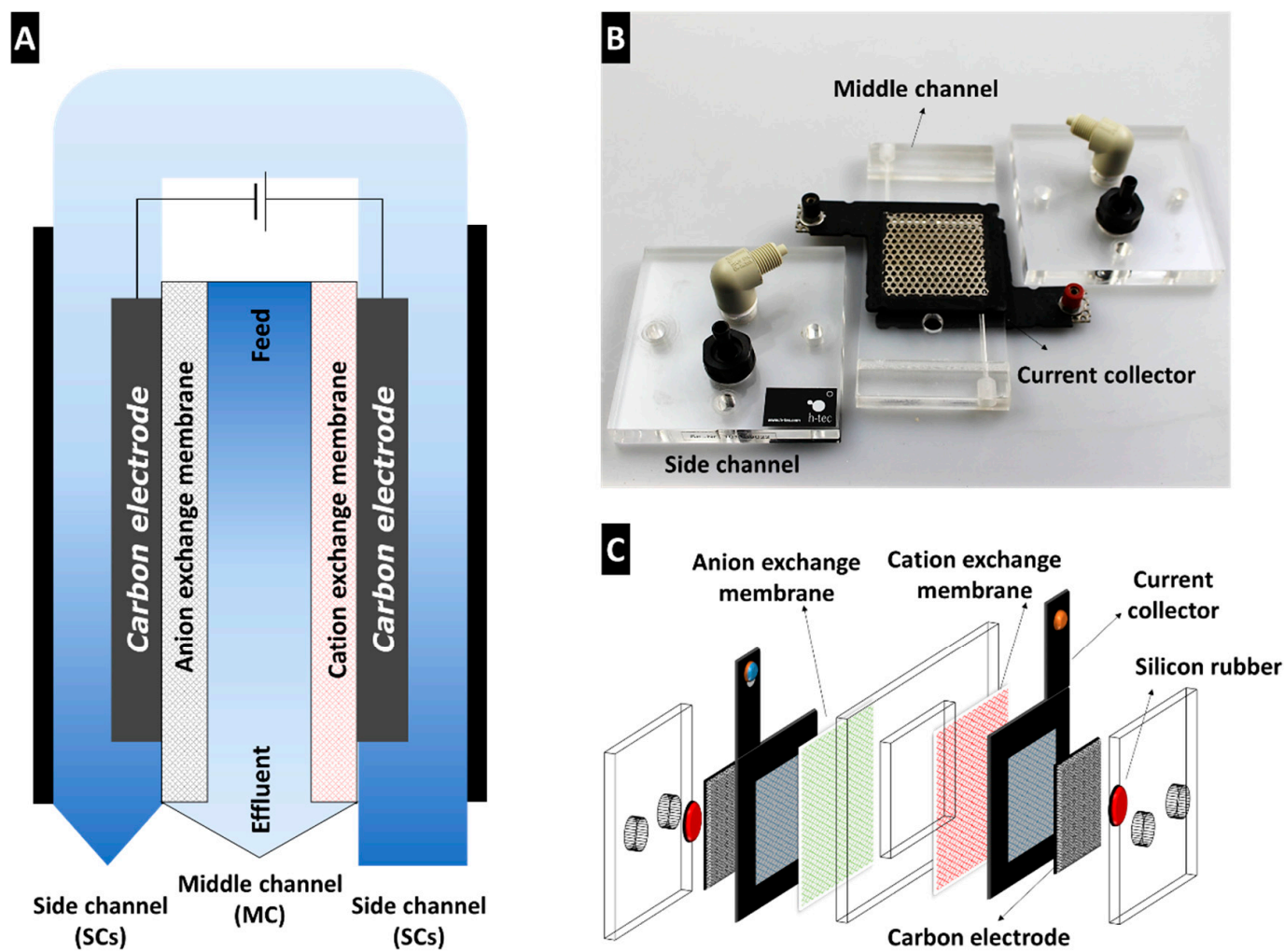

Figure 5. Basic cell architecture of multichannel membrane CDI (MC-MCDI) using channels and ion exchange membranes: (A) Conceptual scheme, (B) frame components, and (C) exploded view of cell assembly (Reprinted with permission from Reference [32]).

Table 3. Comparison of the desalination performance such as salt adsorption capacity (SAC), energy consumption, and the charge efficiency among MCDI, CDI, and MC-MCDI. AC represents activated carbon material, and ACC represents activated carbon cloths.

\begin{tabular}{|c|c|c|c|c|c|c|}
\hline Mode & Material & $\begin{array}{l}\text { Cell Voltage } \\
\text { (V) }\end{array}$ & Feed Concentration (mM) & $\begin{array}{l}\text { SAC (mg/g)/Energy } \\
\text { Consumption (kT) }\end{array}$ & $\begin{array}{c}\text { Charge } \\
\text { Efficiency }\end{array}$ & Ref. \\
\hline \multirow{5}{*}{ MCDI } & \multirow{5}{*}{$\mathrm{AC}$} & $+1.2 / 0$ & 20 & 11.7/n.a. & & [38] \\
\hline & & $+1.2 /-1.2$ & 20 & 13.4/n.a. & & \multirow{2}{*}{ [30] } \\
\hline & & $+1.2 / 0$ & 100 & $6.5 / 24$ & & \\
\hline & & $+1.2 /-1.2$ & 8.5 & 19.5/n.a. & & [46] \\
\hline & & $+1.2 / 0$ & 5 & 10.3/n.a. & & [47] \\
\hline \multirow{5}{*}{ CDI } & ACC & $+1.2 / 0$ & 5 & 16.2/n.a. & & [18] \\
\hline & $\begin{array}{c}\text { Chemical treated } \\
\text { ACC }\end{array}$ & $+1.0 / 0$ & 5 & 15.4/n.a. & & \multirow[t]{2}{*}{ [48] } \\
\hline & Carbon nanotubes & $+1.2 / 0$ & 8.5 & 2.5/n.a. & & \\
\hline & Carbon nanotubes & $+1.2 / 0$ & 34 & 5/n.a. & & [49] \\
\hline & Graphene sponge & $+1.2 / 0$ & 8.5 & 14.6/n.a. & & [50] \\
\hline
\end{tabular}


Table 3. Cont.

\begin{tabular}{|c|c|c|c|c|c|c|}
\hline Mode & Material & $\begin{array}{l}\text { Cell Voltage } \\
\text { (V) }\end{array}$ & Feed Concentration (mM) & $\begin{array}{l}\mathrm{SAC}(\mathrm{mg} / \mathrm{g}) / \text { Energy } \\
\text { Consumption }(\mathrm{kT})\end{array}$ & $\begin{array}{l}\text { Charge } \\
\text { Efficiency }\end{array}$ & Ref. \\
\hline \multirow{7}{*}{$\begin{array}{l}\text { MC- } \\
\text { MCDI }\end{array}$} & \multirow{4}{*}{ ACC(Kynol) } & $+1.2 / 0$ & \multirow{2}{*}{ M: 5 (S: 5) } & $14.1 / \sim 20$ & \multirow{4}{*}{$>90$} & \multirow{4}{*}{15} \\
\hline & & $+1.2 /-1.2$ & & $22.6 / \sim 20$ & & \\
\hline & & $+1.2 / 0$ & \multirow{2}{*}{ M: 5 (S: 1000) } & $29.8 / \sim 20$ & & \\
\hline & & $+1.2 /-1.2$ & & $56.8 / \sim 20$ & & \\
\hline & ACC(Kuraray) & $+1.2 / 0$ & $\begin{array}{l}\mathrm{M}: 10(\mathrm{~S}: 100 \mathrm{NaCl}, \\
\left.\left.\text { 100Na } \mathrm{Na}_{4} \mathrm{FeN}\right)_{6}\right)\end{array}$ & $67.8 / \sim 27$ & $>90$ & [34] \\
\hline & Prussian blue & $+1.0 /-1.0$ & M: 10 (S: 1000) & $52.9 / \sim 38$ & $\sim 98$ & [35] \\
\hline & ACC(Kynol) & $+2.4 / 0.0$ & $\begin{array}{c}\mathrm{M}: 5\left(\mathrm{~S}: 1 \mathrm{M} \mathrm{NaCl} \text { in } \mathrm{H}_{2} \mathrm{O}\right. \\
1 \mathrm{M} \mathrm{NaClO} \\
\text { in PC) }\end{array}$ & $63.5 / 27$ & $\sim 90$ & [33] \\
\hline
\end{tabular}

\subsection{Operational Studies and Principle of Mechanism}

With its key advantages, MC-MCDI has successfully been demonstrated as next-generation cell architecture by various operational studies. In general, MC-MCDI provides a high saline environment to electrodes in the side channels, while the low saline water is fed into the middle channel as treating water. Both channels are independently controlled and separated by ion exchange membranes [32]. The salinity gradient between channels enhances desalination performance with an unprecedented improvement in SAC, high charge efficiency, and low energy consumption (Figure 6) [15]. Particularly, under reverse-voltage operation of $+1.2 \mathrm{~V}$ for charging and $-1.2 \mathrm{~V}$ for discharging, MC-MCDI can be operated as a semi-continuous desalination process for the production of clean water with even greater enhanced desalination performance. As a result, under reverse-voltage operation, MC-MCDI resulted in approximately four times greater desalination performance than the system under operational condition for conventional CDI (see Figure 6A,D).
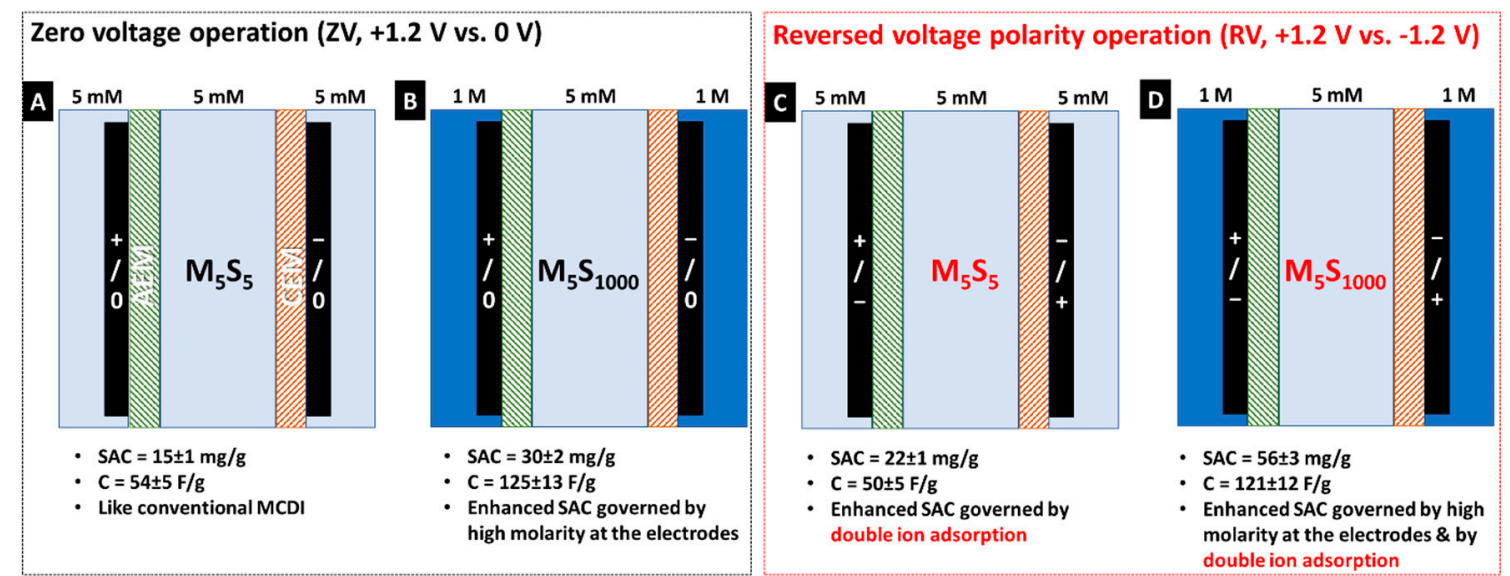

Figure 6. Desalination performance of multichannel membrane CDI (MC-MCDI) with a concentration-gradient operation between the middle and the side channels under zero voltage operation $(\mathrm{ZV},+1.2 \mathrm{~V}$ vs. $0 \mathrm{~V})(\mathbf{A}, \mathbf{B})$ and reverse voltage operation $(\mathrm{RV},+1.2 \mathrm{~V}$ vs. $-1.2 \mathrm{~V})(\mathbf{C}, \mathrm{D})$. The $\mathrm{M}_{5} \mathrm{~S}_{5}$ and $\mathrm{M}_{5} \mathrm{~S}_{1,000}$ indicate the concentration of the middle $(5 \mathrm{mM} \mathrm{NaCl})$ and side channel $(5 \mathrm{mM} \mathrm{NaCl}$ or $1000 \mathrm{mM} \mathrm{NaCl}$ ) (Reprinted with permission from Reference [15]).

The enhancement of desalination performance in MC-MCDI is mainly attributed to the enhanced intrinsic capacitance of the porous carbonaceous electrodes in the high saline environment. Additionally, considering the mechanism of the reverse-voltage operation shown in Figure 7, further enhancement can be interpreted by the block of co-ion repulsion, additional ion flux for charge neutrality, and the double-ion ad/desorption processes. During the first half-cycle (i.e., charging step), co-ions are released from the pores of carbonaceous electrodes in the side channels, while the ion exchange 
membrane blocks those ions due to its permseletivity property. This characteristic phenomenon allows additional migration of counter-ions from the middle channel to balance the charge neutrality in the side channels. Consequently, the feed stream in the middle channel is desalinated, while the side channel is concentrated. During the second half-cycle (i.e., discharging step), co-ions can migrate from the side channels to the middle channel through the ion exchange membrane, producing concentrated effluent in the middle channel and desalinated solution in the side channels.
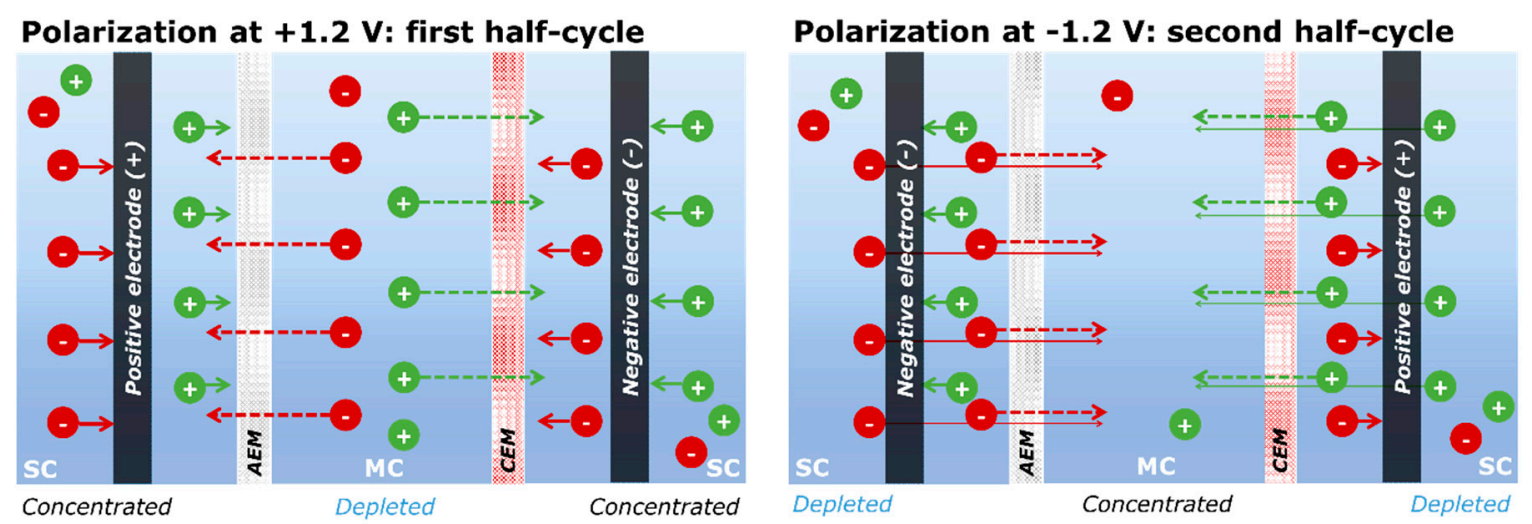

Figure 7. Ion removal mechanism of MC-MCDI in semi-continuous operation: Anion exchange membrane (AEM) and cation exchange membrane (CEM), and MC and SC denote the middle and side channels, respectively. (Reprinted with permission from Reference [32]).

Furthermore, the benefit of the salinity gradient in MC-MCDI was also thoroughly examined in battery electrodes like Prussian blue analogs (Figure 8A) [35]. Although the battery type electrodes have garnered attention because of their high ion removal capacity, the mass transfer at the interface of the electrode and low saline feed is too limited to maintain the long-term stability. As shown in Figure 8B, using the MC-MCDI, ion removal capacity, and the maximum salt removal rate demonstrated to a three-fold increase as the side channel concentration increased from 10 to $1000 \mathrm{mM}$, preventing performance degradation over 100 cycles [35].

\section{A}

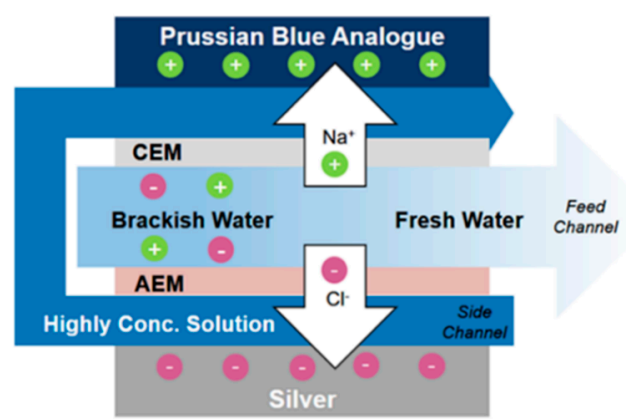

B

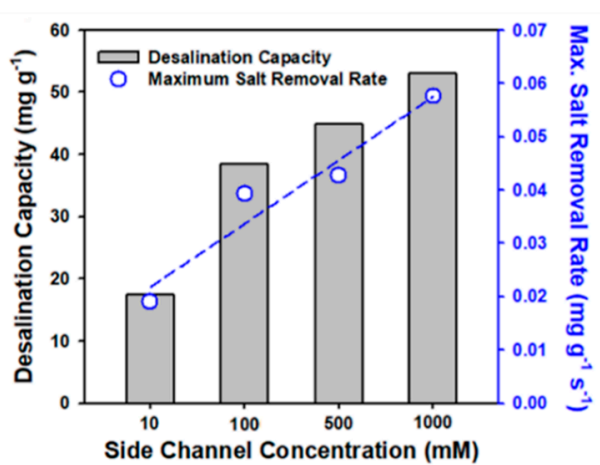

Figure 8. (A) Schematic illustration and (B) desalination capacity as well as the maximum salt removal rate of multichannel membrane CDI (MC-MCDI) using battery type electrodes (Reprinted with permission from [35]. Copyright (2019) American Chemical Society).

It is clear that the salinity gradient in MC-MCDI could improve desalination performance such as ion removal capacity, charge efficiency, and mass transfer. It should be noted that the exceptional desalination performance is accomplished with a simple operational condition and without a complicated cell module or any additional electrode modifications. 


\subsection{Applications of MC-MCDI}

Besides high saline solution, various types of solutions, such as an organic electrolyte and a redox couple, can be introduced as a supporting electrolyte in the side channels of MC-MCDI [33,34,51]. Using various supporting electrolytes, MC-MCDI reaches beyond the confines of its conventional operations, including the extension of cell voltage [33], ion removal assisted by the redox couple reaction [34,51], and continuous desalination [34]. MC-MCDI with organic electrolyte as the supporting electrolyte could optimize the cell voltage up to $2.4 \mathrm{~V}$ which is a two-fold increase in a stable operating cell voltage $\left(\mathrm{V}_{\text {cell }}=1.2 \mathrm{~V}\right)$ of $\mathrm{CDI}$ for water desalination [33]. For instance, the cation side of the side channel is filled with the aqueous medium, while the anion side of the side channel is filled with the organic electrolyte such as propylene carbonate. As a result, highly enhanced SAC (63.5 mg/g) was achieved with comparable energy consumption and high charge efficiency (Table 3). Since the charge is linearly proportional to the operation voltage (Gouy-Chapman-Stern theory), the extended cell voltage significantly increased the desalination capacity of the porous carbon electrode. In addition, the MC-MCDI could utilize the redox couple such as iodide and ferrocyanide, to further enhance the desalination performance along with the use of the adsorption capacity (Figure 9A) [33,51]. The system, assisted by the redox reaction, showed a remarkable desalination performance even over long-term operation with its fast kinetics and high reversibility governed by thin-layer electrochemistry [52]. Predominantly, the reversible redox reaction along the side channels allowed sustainable desalination of the treating water. This application highlights that the MC-MCDI with the redox could be developed as a desalination system for highly concentrated water up to seawater level [34].

A

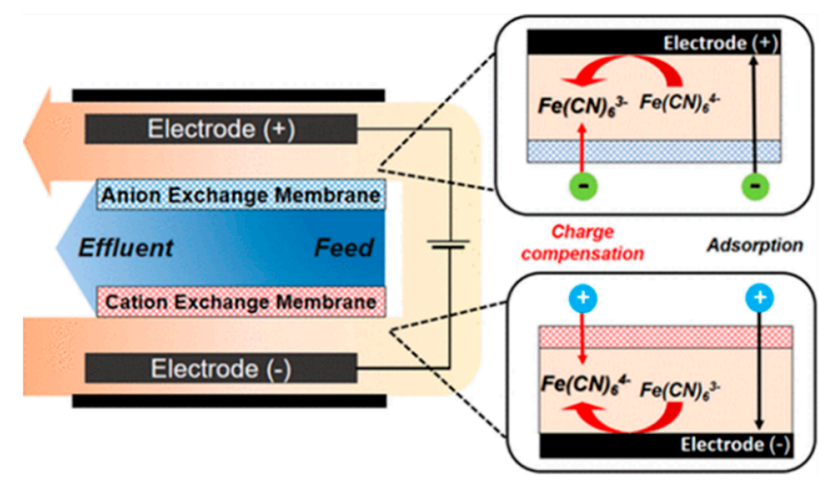

B

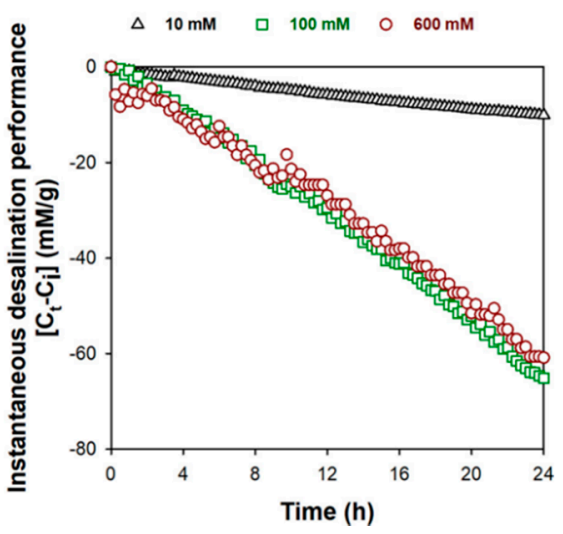

Figure 9. (A) Schematic illustration and (B) continuous desalination operation of CDI assisted by redox couple reaction (Reprinted with permission from [34]. Copyright (2019) American Chemical Society).

\section{Conclusions and Future Prospect}

With significant growth in the CDI field over the past few decades, a tremendous research effort has provided various scientific and industrial breakthroughs in CDI technologies by exploring new electrode materials, as well as theoretical studies. Additionally, significant improvements have been made with the systematic advancement such as MCDI, HCDI, i-CDI, and FCDI. In particular, MC-MCDI opens various opportunities and shows many possibilities to overcome key limitations of the conventional CDI with a unique cell architecture using multichannel.

Despite its compelling desalination performance, further investigations should be performed to investigate the practical use of MC-MCDI. For further success of MC-MCDI as the next-generation of CDI architecture, the following issues must be studied and resolved by future research: (1) A relatively complicated cell design is vulnerable to expand its desalination capacity by stacking the multiple-unit-cells, (2) it remains unclear if the ion removal mechanism originates from the electrosorption in nanopores of the carbon electrode or just from ionic movement through the 
membrane due to the electrical field, and (3) its performance is still limited because the studies were exclusively evaluated with the porous carbonaceous materials. Moreover, it is important to conduct system optimization as well as various parameter studies of the MC-MCDI for practical use of the system. In conclusion, it is very promising that MC-MCDI is an innovative CDI system not only to enhance the desalination performance but also to expand the scope of the CDI system beyond the low salinity desalination.

Author Contributions: C.K. and N.K. conceived and organized the paper; C.K. and N.K. wrote the first draft; J.L., S.K., S.P.H., C.L., and J.Y. reviewed and edited the paper. All authors have read and agreed to the published version of the manuscript.

Acknowledgments: This work has supported by the National Research Foundation of Korea (NRF) grant funded by the Korea government (MSIT) (NRF-2019R1G1A1003336) and by the research grant of the Waste to Energy Recycling Human Resource Development Project of Korea Ministry of Environment (ME).

Conflicts of Interest: The authors declare no conflict of interest.

\section{References}

1. Suss, M.; Porada, S.; Sun, X.; Biesheuvel, P.; Yoon, J.; Presser, V. Water desalination via capacitive deionization: What is it and what can we expect from it? Energy Environ. Sci. 2015, 8, 2296-2319. [CrossRef]

2. Porada, S.; Zhao, R.; Van Der Wal, A.; Presser, V.; Biesheuvel, P. Review on the science and technology of water desalination by capacitive deionization. Prog. Mater. Sci. 2013, 58, 1388-1442. [CrossRef]

3. AlMarzooqi, F.A.; Al Ghaferi, A.A.; Saadat, I.; Hilal, N. Application of capacitive deionisation in water desalination: A review. Desalination 2014, 342, 3-15. [CrossRef]

4. Yoon, H.; Lee, J.; Kim, S.; Yoon, J. Review of concepts and applications of electrochemical ion separation (EIONS) process. Sep. Purif. Technol. 2018, 215, 190-207. [CrossRef]

5. Anderson, M.A.; Cudero, A.L.; Palma, J. Capacitive deionization as an electrochemical means of saving energy and delivering clean water. Comparison to present desalination practices: Will it compete? Electrochim. Acta 2010, 55, 3845-3856. [CrossRef]

6. Zhao, R.; Porada, S.; Biesheuvel, P.; Van der Wal, A. Energy consumption in membrane capacitive deionization for different water recoveries and flow rates, and comparison with reverse osmosis. Desalination 2013, 330, 35-41. [CrossRef]

7. Zhang, D.; Yan, T.; Shi, L.; Peng, Z.; Wen, X.; Zhang, J. Enhanced capacitive deionization performance of graphene/carbon nanotube composites. J. Mater. Chem. 2012, 22, 14696-14704. [CrossRef]

8. Kim, C.; Lee, J.; Kim, S.; Yoon, J. $\mathrm{TiO}_{2}$ sol-gel spray method for carbon electrode fabrication to enhance desalination efficiency of capacitive deionization. Desalination 2014, 342, 70-74. [CrossRef]

9. Lee, L.Y.; Ng, H.Y.; Ong, S.L.; Tao, G.; Kekre, K.; Viswanath, B.; Lay, W.; Seah, H. Integrated pretreatment with capacitive deionization for reverse osmosis reject recovery from water reclamation plant. Water Res. 2009, 43, 4769-4777. [CrossRef]

10. Tan, C.; He, C.; Tang, W.; Kovalsky, P.; Fletcher, J.; Waite, T.D. Integration of photovoltaic energy supply with membrane capacitive deionization (MCDI) for salt removal from brackish waters. Water Res. 2018, 147, 276-286. [CrossRef]

11. Liu, Y.; Nie, C.; Liu, X.; Xu, X.; Sun, Z.; Pan, L. Review on carbon-based composite materials for capacitive deionization. RSC Adv. 2015, 5, 15205-15225. [CrossRef]

12. Jia, B.; Zhang, W. Preparation and application of electrodes in capacitive deionization (CDI): A state-of-art review. Nanoscale Res. Lett. 2016, 11, 64. [CrossRef] [PubMed]

13. Huang, W.; Zhang, Y.; Bao, S.; Song, S. Desalination by capacitive deionization with carbon-based materials as electrode: A review. Surf. Rev. Lett. 2013, 20, 1330003. [CrossRef]

14. Oladunni, J.; Zain, J.H.; Hai, A.; Banat, F.; Bharath, G.; Alhseinat, E. A comprehensive review on recently developed carbon based nanocomposites for capacitive deionization: From theory to practice. Sep. Purif. Technol. 2018, 207, 291-320. [CrossRef]

15. Kim, C.; Lee, J.; Srimuk, P.; Aslan, M.; Presser, V. Concentration-gradient multichannel flow-stream membrane capacitive deionization cell for high desalination capacity of carbon electrodes. ChemSusChem 2017, 10, 4914-4920. [CrossRef] [PubMed] 
16. Lee, J.; Kim, S.; Kim, C.; Yoon, J. Hybrid capacitive deionization to enhance the desalination performance of capacitive techniques. Energy Environ. Sci. 2014, 7, 3683-3689. [CrossRef]

17. Lee, J.; Kim, S.; Yoon, J. Rocking chair desalination battery based on prussian blue electrodes. ACS Omega 2017, 2, 1653-1659. [CrossRef]

18. Kim, C.; Srimuk, P.; Lee, J.; Fleischmann, S.; Aslan, M.; Presser, V. Influence of pore structure and cell voltage of activated carbon cloth as a versatile electrode material for capacitive deionization. Carbon 2017, 122, 329-335. [CrossRef]

19. Srimuk, P.; Kaasik, F.; Krüner, B.; Tolosa, A.; Fleischmann, S.; Jäckel, N.; Tekeli, M.C.; Aslan, M.; Suss, M.E.; Presser, V. MXene as a novel intercalation-type pseudocapacitive cathode and anode for capacitive deionization. J. Mater. Chem. A 2016, 4, 18265-18271. [CrossRef]

20. Srimuk, P.; Husmann, S.; Presser, V. Low voltage operation of a silver/silver chloride battery with high desalination capacity in seawater. RSC Adv. 2019, 9, 14849-14858. [CrossRef]

21. Farmer, J.C.; Fix, D.V.; Mack, G.V.; Pekala, R.W.; Poco, J.F. Capacitive deionization of $\mathrm{NaCl}_{\text {and }} \mathrm{NaNO}_{3}$ solutions with carbon aerogel electrodes. J. Electrochem. Soc. 1996, 143, 159-169. [CrossRef]

22. Suss, M.E.; Baumann, T.F.; Bourcier, W.L.; Spadaccini, C.M.; Rose, K.A.; Santiago, J.G.; Stadermann, M. Capacitive desalination with flow-through electrodes. Energy Environ. Sci. 2012, 5, 9511-9519. [CrossRef]

23. Gao, X.; Omosebi, A.; Landon, J.; Liu, K. Surface charge enhanced carbon electrodes for stable and efficient capacitive deionization using inverted adsorption-desorption behavior. Energy Environ. Sci. 2015, 8, 897-909. [CrossRef]

24. Kim, S.; Lee, J.; Kim, C.; Yoon, J. $\mathrm{Na}_{2} \mathrm{FeP}_{2} \mathrm{O}_{7}$ as a novel material for hybrid capacitive deionization. Electrochim. Acta 2016, 203, 265-271. [CrossRef]

25. Smith, K.C.; Dmello, R. Na-ion desalination (NID) enabled by Na-blocking membranes and symmetric Na-intercalation: Porous-electrode modeling. J. Electrochem. Soc. 2016, 163, A530-A539. [CrossRef]

26. Pasta, M.; Wessells, C.D.; Cui, Y.; La Mantia, F. A desalination battery. Nano Lett. 2012, 12, 839-843. [CrossRef]

27. Jeon, S.-I.; Park, H.-R.; Yeo, J.-G.; Yang, S.; Cho, C.H.; Han, M.H.; Kim, D.K. Desalination via a new membrane capacitive deionization process utilizing flow-electrodes. Energy Environ. Sci. 2013, 6, 1471-1475. [CrossRef]

28. Doornbusch, G.; Dykstra, J.; Biesheuvel, P.; Suss, M. Fluidized bed electrodes with high carbon loading for water desalination by capacitive deionization. J. Mater. Chem. A 2016, 4, 3642-3647. [CrossRef]

29. Tang, W.; He, D.; Zhang, C.; Kovalsky, P.; Waite, T.D. Comparison of Faradaic reactions in capacitive deionization (CDI) and membrane capacitive deionization (MCDI) water treatment processes. Water Res. 2017, 120, 229-237. [CrossRef]

30. Biesheuvel, P.; Zhao, R.; Porada, S.; Van der Wal, A. Theory of membrane capacitive deionization including the effect of the electrode pore space. J. Colloid Interface Sci. 2011, 360, 239-248. [CrossRef]

31. Porada, S.; Borchardt, L.; Oschatz, M.; Bryjak, M.; Atchison, J.; Keesman, K.; Kaskel, S.; Biesheuvel, P.; Presser, V. Direct prediction of the desalination performance of porous carbon electrodes for capacitive deionization. Energy Environ. Sci. 2013, 6, 3700-3712. [CrossRef]

32. Kim, C.; Srimuk, P.; Lee, J.; Aslan, M.; Presser, V. Semi-continuous capacitive deionization using multi-channel flow stream and ion exchange membranes. Desalination 2018, 425, 104-110. [CrossRef]

33. Kim, C.; Srimuk, P.; Lee, J.; Presser, V. Enhanced desalination via cell voltage extension of membrane capacitive deionization using an aqueous/organic bi-electrolyte. Desalination 2018, 443, 56-61. [CrossRef]

34. Kim, N.; Hong, S.P.; Lee, J.; Kim, C.; Yoon, J. High-desalination performance via redox couple reaction in the multichannel capacitive deionization system. ACS Sustain. Chem. Eng. 2019, 7, 16182-16189. [CrossRef]

35. Lee, J.; Lee, J.; Ahn, J.; Jo, K.; Hong, S.P.; Kim, C.; Lee, C.; Yoon, J. Enhancement in desalination performance of battery electrodes via improved mass transport using a multichannel flow system. ACS Appl. Mater. Interfaces 2019, 11, 36580-36588. [CrossRef] [PubMed]

36. Kang, J.; Kim, T.; Shin, H.; Lee, J.; Ha, J.-I.; Yoon, J. Direct energy recovery system for membrane capacitive deionization. Desalination 2016, 398, 144-150. [CrossRef]

37. Tan, C.; He, C.; Fletcher, J.; Waite, T.D. Energy recovery in pilot scale membrane CDI treatment of brackish waters. Water Res. 2019, 168, 115146. [CrossRef]

38. Zhao, R.; Satpradit, O.; Rijnaarts, H.; Biesheuvel, P.; Van der Wal, A. Optimization of salt adsorption rate in membrane capacitive deionization. Water Res. 2013, 47, 1941-1952. [CrossRef]

39. Kim, T.; Yoon, J. CDI ragone plot as a functional tool to evaluate desalination performance in capacitive deionization. RSC Adv. 2015, 5, 1456-1461. [CrossRef] 
40. Zhao, R.; Biesheuvel, P.; Van der Wal, A. Energy consumption and constant current operation in membrane capacitive deionization. Energy Environ. Sci. 2012, 5, 9520-9527. [CrossRef]

41. Wang, L.; Dykstra, J.; Lin, S. Energy efficiency of capacitive deionization. Environ. Sci. Technol. 2019, 53, 3366-3378. [CrossRef] [PubMed]

42. Ahn, J.; Lee, J.; Kim, S.; Kim, C.; Lee, J.; Biesheuvel, P.; Yoon, J. High performance electrochemical saline water desalination using silver and silver-chloride electrodes. Desalination 2020, 476, 114216. [CrossRef]

43. Tang, W.; Liang, J.; He, D.; Gong, J.; Tang, L.; Liu, Z.; Wang, D.; Zeng, G. Various cell architectures of capacitive deionization: Recent advances and future trends. Water Res. 2019, 150, 225-251. [CrossRef] [PubMed]

44. Kim, S.; Kim, C.; Lee, J.; Kim, S.; Lee, J.; Kim, J.; Yoon, J. Hybrid electrochemical desalination system combined with an oxidation process. ACS Sustain. Chem. Eng. 2018, 6, 1620-1626. [CrossRef]

45. Porada, S.; Sales, B.; Hamelers, H.; Biesheuvel, P. Water desalination with wires. J. Phys. Chem. Lett. 2012, 3 , 1613-1618. [CrossRef] [PubMed]

46. Wu, T.; Wang, G.; Zhan, F.; Dong, Q.; Ren, Q.; Wang, J.; Qiu, J. Surface-treated carbon electrodes with modified potential of zero charge for capacitive deionization. Water Res. 2016, 93, 30-37. [CrossRef]

47. Aslan, M.; Zeiger, M.; Jäckel, N.; Grobelsek, I.; Weingarth, D.; Presser, V. Improved capacitive deionization performance of mixed hydrophobic/hydrophilic activated carbon electrodes. J. Phys. Condens. Matter 2016, 28, 114003. [CrossRef]

48. Gao, X.; Porada, S.; Omosebi, A.; Liu, K.-L.; Biesheuvel, P.; Landon, J. Complementary surface charge for enhanced capacitive deionization. Water Res. 2016, 92, 275-282. [CrossRef]

49. Wang, S.; Wang, D.; Ji, L.; Gong, Q.; Zhu, Y.; Liang, J. Equilibrium and kinetic studies on the removal of $\mathrm{NaCl}$ from aqueous solutions by electrosorption on carbon nanotube electrodes. Sep. Purif. Technol. 2007, 58, 12-16. [CrossRef]

50. Xu, X.; Sun, Z.; Chua, D.H.; Pan, L. Novel nitrogen doped graphene sponge with ultrahigh capacitive deionization performance. Sci. Rep. 2015, 5, 11225. [CrossRef]

51. Lee, J.; Srimuk, P.; Carpier, S.; Choi, J.; Zornitta, R.L.; Kim, C.; Aslan, M.; Presser, V. Confined redox reactions of iodide in carbon nanopores for fast and energy-efficient desalination of brackish water and seawater. ChemSusChem 2018, 11, 3460-3472. [CrossRef] [PubMed]

52. Akinwolemiwa, B.; Peng, C.; Chen, G.Z. Redox electrolytes in supercapacitors. J. Electrochem. Soc. 2015, 162, A5054-A5059. [CrossRef] 